\title{
Correction to: H. William Schnaper-Life course journey of a true Mensch
}

\author{
Laurence Greenbaum ${ }^{1}$ - Victoria Norwood ${ }^{2}$ - Eileen Brewer ${ }^{3}$. William Smoyer ${ }^{4}$ Marva Moxey-Mims ${ }^{5}$. \\ Joseph Flynn ${ }^{6} \cdot$ Barbara Fivush $^{7} \cdot$ Patrick Brophy $^{8} \cdot$ Brad Warady $^{9} \cdot$ Sandra Watkins $^{6} \cdot$ Isidro Salusky $^{10} \cdot$ Rick Kaskel $^{11}$
}

Published online: 20 August 2021

() IPNA 2021

\section{Correction to: Pediatr Nephrol}

\section{https://doi.org/10.1007/s00467-021-04959-3}

The article "H. William Schnaper-Life course journey of a true Mensch", written by Laurence Greenbaum, Victoria Norwood, Eileen Brewer, William Smoyer, Marva Moxey-Mims, Joseph Flynn, Barbara Fivush, Patrick Brophy, Brad Warady, Sandra Watkins, Isidro Salusky \& Rick Kaskel, was originally published online on the publisher's internet portal on March $17^{\text {th }} 2021$ with Open Access under a "Creative Commons Attribution (CC BY) license 4.0". With the author's/authors' decision to cancel Open Access, the copyright of the article changed on July $20^{\text {th }} 2021$ to (C) IPNA 2021 with all rights reserved.
Publisher's note Springer Nature remains neutral with regard to jurisdictional claims in published maps and institutional affiliations.
The online version of the original article can be found at https:// doi.org/10.1007/s00467-021-04959-3.

\section{Rick Kaskel}

frederick.kaskel@einsteinmed.org

Emory University School of Medicine, Atlanta, GA, USA

2 University of Virginia School of Medicine, Charlottesville, VA, USA

3 Baylor College of Medicine, Houston, TX, USA

4 Ohio State University School of Biomedical Science:, The Ohio State University College of Medicine, Columbus, $\mathrm{OH}$, USA

5 George Washington University Medical Center, Washington, DC, USA
6 University of Washington Seattle Campus: University of Washington, Seattle, WA, USA

7 Johns Hopkins University School of Medicine, Baltimore, MD, USA

8 University of Rochester Medical Center, Rochester, NY, USA

9 University of Kansas City: University of Missouri Kansas City, Kansas City, MO, USA

10 University of California Los Angeles, Los Angeles, CA, USA

11 Montefiore Medical Center, New York City, NY, USA 